\title{
Severe burn injury in late pregnancy: a case report and literature review
}

\author{
Yan Shi, Xiong Zhang, Bo-Gao Huang, Wen-Kui Wang and Yan Liu*
}

\begin{abstract}
The management of serious burn injuries during pregnancy is an unsolved clinical problem because of the low incidence of this disease. Although it has been documented that the effect of burns on fetal and maternal survival is detrimental, there have been conflicting reports among the different burn centers regarding the mortality of burned pregnant women and the management of burn patients during pregnancy. We report a case of severe burn in late pregnancy treated at our burn center. Additionally, we searched and summarized the literature concerning the management of pregnant patients to provide useful information for their treatment.
\end{abstract}

Keywords: Burn, Pregnancy, Fluid resuscitation

\section{Introduction}

The management of serious burn injuries during pregnancy needs to be better studied and standardized due to the low incidence of this disastrous condition. In general, severe burn injury in pregnant patients is more common in developing countries because most of the case reports have come from low-income countries [1-4]. The maternal mortality and morbidity in the literature concerning severe burn injury in pregnant patients are usually significantly higher than those in the general population with the same degree of injury, although there are tremendous differences among different reports [3,5]. As early as the 1990s, Rode et al., reported that when over $50 \%$ of the total body area was burned, the mother's survival was unlikely [6]. Since then, the mortality and morbidity rates have not changed. In a 9-year prospective study conducted on 51 pregnant women with a severe burn injury, the authors reported that both the maternal and fetal mortality rates reached $100 \%$ in the pregnant women with the total burned body surface area exceeding $40 \%$ total body surface area (TBSA) [7]. Recently, however, in a 6-year cross-sectional study, 39 (1.88\%) women were found to be pregnant among 2,067 women with a severe burn injury, and the mortality rate of all the pregnant women reached $66.7 \%$ with more than $50 \%$ death rate when the burn area exceeded $60 \%$ [8]. It is widely recognized that the effect of

\footnotetext{
*Correspondence: rjliuyan@126.com

Department of Burn and Plastic Surgery, Shanghai Jiaotong University, School of Medicine Affiliated Ruijin Hospital, Shanghai 200025, China
}

burns on fetal and maternal survival is detrimental, and there is a positive relationship between the percentage of maternal total body burn area and maternal and fetal mortality, as well as premature delivery [9]. However, Amy et al. [10] reported that pregnancy does not alter the maternal outcome after thermal injury. Because there were conflicting reports among different burn centers and an enormously high mortality in pregnant women with severe burn injury, collecting more information and reaching a consensus on the management of burns in pregnancy are necessary.

\section{Case report}

The patient was a 28-year-old woman who was referred to our Burn Institute $1.5 \mathrm{~h}$ after a flame burned her head, trunk, and limbs. The patient had a distressed facial expression and was cooperative in the physical examination. She had no breathing difficulty, although obvious swelling, particularly on the head, was observed. No ashes or blisters were found on the oropharyngeal mucosa by laryngoscopy examination. Physical examination data on admission were as follows: body weight, 56 $\mathrm{kg}$; blood pressure, 132/67 mmHg; pulse rate, $88 \mathrm{bpm}$; body temperature, $36.8^{\circ} \mathrm{C}$; and respiratory rate, $15 \mathrm{bpm}$. The burn wounds were distributed on the face, neck, trunk, and limbs, and the total burn area was 50\% TBSA. Wounds were presented as red, or red and white in appearance, and parts of them were dry with diminished sensation. The laboratory results were as follows: 
blood routine examination: WBC, $18.64 \times 10^{9} / \mathrm{L}$; neutrophil granulocyte, 90.3\%; Hgb, 105 g/L; RBC, $4.03 \times 10^{12} / \mathrm{L}$; Hct, 0.329 ; platelet, $296 \times 10^{9} / \mathrm{L}$. The liver and kidney function indexes were all in the normal range except that the total protein level was $50 \mathrm{~g} / \mathrm{L}$ and the albumin level was $24 \mathrm{~g} / \mathrm{L}$. The obstetric examination results were as follows: The patient was 35 weeks and 5 days pregnant, the uterine fundus was halfway between the umbilicus and xiphoid process, and the fetal outline was palpable. No vaginal bleeding or discharge was observed, and uterine contraction was not palpable. Fetal movements were occasionally felt. The cervix was not open, and the fetal membranes had not broken. The fetal heart rate (FHR) was 150 $\mathrm{bpm}$. There was no gestational hypertension, gestational diabetes, or other combined diseases reported. The admission diagnosis was that the flame burned 50\% TBSA (superficial second-degree 20\% TBSA, deep partial thickness burn 30\% TBSA) with a third-trimester pregnancy.

During emergency treatment, lactate Ringer's solution was infused for fluid resuscitation, and $1,500 \mathrm{~mL}$ of lactate Ringer's solution was infused during the first $9 \mathrm{~h}$ after injury. The burns were covered with Vaseline gauze after simple wound cleaning. Nine hours after the injury, after consulting and discussing with the obstetrician, a cesarean section was performed under spinal epidural anesthesia, and a live baby girl was delivered. The surgery lasted approximately $1 \mathrm{~h}$, and the blood pressure was stable during the surgery. The Hgb level after the surgery was $97 \mathrm{~g} / \mathrm{L}$. The baby had a body weight of 2,220 g and a body length of $46 \mathrm{~cm}$ with APGAR scores of 10, 10, and 10 '. The vital signs of the patient were stable during surgery. After delivery of the baby, intravenous fluid resuscitation was continued for the patient using the Ruijin (Resuscitation) formula. Ruijin's formula involves the infusion of a crystalloid solution, which comprised primarily lactated Ringer's solution and/or colloids, usually plasma, at a rate of $1.5 \mathrm{~mL} / \mathrm{kg} /$ percentage of the burned body surface area for the first $24 \mathrm{~h}$ and half of the amount of the actually infused crystalloid and colloid solution for the second $24 \mathrm{~h}$. In addition, 2,000 3,000 $\mathrm{mL}$ of physicaldemanding water was applied every $24 \mathrm{~h}$ after injury. The type and volume of the solution delivered for liquid resuscitation are summarized in Table 1 . The hourly urine output was $50 \sim 350 \mathrm{~mL}$ during the first $48 \mathrm{~h}$ after the burn injury. The treatment for the patient included the application of silver sulfadiazine cream on the wounds when the dressing was changed every 2 days, infusion of imipenem for the antimicrobial prophylaxis of infection, and administration of oxytocin and Chinese herbal medication to promote uterine involution. No systemic infection or dysfunction of internal organs was found during the patient's stay in the hospital. The patient discharged herself without postpartum complications at 15 days after injury due to financial reasons. At discharge, the superficial second-degree and part of the deep partial thickness burn wounds that were relatively superficial were healed, and less than 10\% TBSA deep partial thickness burn wounds remained on the neck, right upper limb, and both legs. No signs of difficulty of healing that could imply the connection of impaired healing and pregnancy were observed. Physical examination results were as follows: blood pressure, 119/76 mmHg; pulse rate, $90 \mathrm{bpm}$; body temperature, $36.4^{\circ} \mathrm{C}$; and respiratory rate, $17 \mathrm{bpm}$. Laboratory results were as follows: blood routine examination: WBC, $8.76 \times 10^{9} / \mathrm{L}$; neutrophil granulocyte, 71.3\%; Hgb, $111 \mathrm{~g} / \mathrm{L}$; RBC, $4.12 \times 10^{12} / \mathrm{L}$; Hct, 0.337; platelet, $359 \times 10^{9} / \mathrm{L}$; glutamic pyruvic transaminase, $19 \mathrm{IU} / \mathrm{L}$; glutamic-oxalacetic transaminase, $23 \mathrm{IU} / \mathrm{L}$; alkaline phosphatase, $81 \mathrm{IU} / \mathrm{L}$; TP, $71 \mathrm{~g} / \mathrm{L}$; albumin, $36 \mathrm{~g} / \mathrm{L}$; urea nitrogen, $3.6 \mathrm{mmol} / \mathrm{L}$; creatinine, $37 \mu \mathrm{mol} / \mathrm{L}$.

\section{Discussion}

The hemodynamic changes for the severe burn patient in late pregnancy showed specific characteristics. The cardiac output and volume of circulating blood of the pregnant woman started increasing from approximately 6 to 8 weeks and gradually reached a peak at 32 34 weeks of pregnancy, an increase of $30 \% \sim 45 \%$ in total volume $(1,500$ $\mathrm{mL}$ on average). After delivery, the increased cardiac output and volume of circulating blood were gradually restored to the basal level at approximately 2-3 weeks [11]. Although it is well known that intense resuscitation is needed for pregnant women, there are no detailed instructions regarding what is the proper amount of fluid for those patients. There are many resuscitation formulas adopted by different burn units [12], and Ruijin's formula was used for guiding the burn patients' resuscitation at our department. Ruijin's formula is a modification of Evans formula and is more suitable for patients of Asian descent and has been applied in several burn centers of China for more than 50 years. Ruijin's formula and the

Table 1 Volume of fluid resuscitation $(\mathrm{mL})$

\begin{tabular}{|c|c|c|c|c|c|}
\hline Times & $\begin{array}{l}\text { Estimated crystalloid } \\
\text { and colloid solution }\end{array}$ & $\begin{array}{l}\text { Actual infused crystalloid } \\
\text { and colloid solution }\end{array}$ & $\begin{array}{l}\text { Actual infused } \\
\text { crystalloid solution }\end{array}$ & $\begin{array}{l}\text { Actual infused } \\
\text { colloid solution }\end{array}$ & Urine output \\
\hline First $24 \mathrm{~h}$ & 4,200 & 2,300 & 1,500 & 800 & 1,985 \\
\hline Second $24 \mathrm{~h}$ & 2,100 & 1,100 & 500 & 600 & 3,840 \\
\hline Third $24 \mathrm{~h}$ & & & & 400 & 4,245 \\
\hline
\end{tabular}

The solution delivered during surgery (which was excluded from the total fluid resuscitation): 1,000 mL of lactate Ringer's solution, $500 \mathrm{~mL}$ of normal saline, and $600 \mathrm{~mL}$ of plasma. 
Third Military Medical University (TMMU) formula are the most influential formulas in China. Different from the TMMU formula, Ruijin's formula sets the ratio of crystalloid solution versus colloid solution at 1:1. In this case, the estimated volume of the crystalloid and colloid solution for the first $24 \mathrm{~h}$ was $4,200 \mathrm{~mL}$; the actual infusion amount was $4,400 \mathrm{~mL}$ (including an intra-operative amount of 2,100 mL). The actual infusion amount of the second $24 \mathrm{~h}$ was $1,100 \mathrm{~mL}$, which was $52.38 \%$ of the estimated amount (half of 4,200 mL). Considering the extra requirement for the surgery, the actual infusion amount for the first $24 \mathrm{~h}$ was much lower than the estimated amount. The urine amount at the first $48 \mathrm{~h}$ had reached $50 \sim 350 \mathrm{~mL} / \mathrm{h}$, which was significantly higher than $0.5 \sim 1$ $\mathrm{mL} / \mathrm{kg} / \mathrm{h}$ of urine output, which is the general requirement for an effective resuscitation. We believed that the increased cardiac output and body circulating volume, particularly when the baby was delivered, would make the patient more tolerant to fluid loss. Therefore, the infusion volume during shock resuscitation for these maternity patients could be reduced appropriately depending on the urine volume and general condition. Based on our literature search, ours is the first case report to suggest decreasing the infusion volume of fluid resuscitation, particularly after the fetus is delivered. Unfortunately, we only monitored the heart rate, blood pressure, and urine output for the guidance of resuscitation. Indeed, it will be greatly helpful to utilize more hemodynamic parameters to judge the patients' circulation status and heart function and guide resuscitation.

Pregnancy with burns not only makes treatment for the mother difficult but also threatens the fetus. Within the context of ensuring the survival of the neonate, late pregnancy patients should terminate their pregnancy as early as possible to prevent fetal distress, improve the survival possibility of the fetus, and simplify the management of pregnant women. The correct judgment of pregnant week is crucial. If the gestational week is uncertain and prenatal examination is not performed routinely, the measurement of the physical indexes of the fetus, including the biparietal diameter, head circumference, and height of the femur using B-mode ultrasound, will be useful for the assessment of gestational age and maturity of the fetus. If the fetus is still immature, continuation of pregnancy could be considered under close monitoring, but the fetus is under the risk of drug toxicity due to the treatment strategies. Much literature has indicated that septicemia and sepsis are the main causes of death in pregnant women $[8,13]$, and the administration of antibiotics is inevitable. The US Food and Drug Administration (FDA) has divided antibiotics into five grades (A, B, C, D, and X) according to the possible side effects for the fetus. Penicillins, macrolides, cephalosporins, lincomycin, and clindamycin belong to grade B drugs, which are safe for pregnant women and could be used during pregnancy. Quinolones, itraconazole, and fluconazole belong to grade $\mathrm{C}$ drugs, and animal experiments have revealed negative influences on the fetus; therefore, they are selected only when potential benefits exceed potential risks. Silver sulfadiazine could be absorbed from the wounds, and the absorption amount is related to the applied area and duration. Research had reported that the average $\mathrm{Ag}^{+}$concentration in the blood reaches $190 \mathrm{ng} / \mathrm{mL}$ at 10 days after application for patients with $<35 \%$ TBSA, and the $\mathrm{Ag}^{+}$was observed to deposit in the liver and kidneys [14]. Extensive area application of silver sulfadiazine should be avoided for pregnant women with burns because absorption of sulfonamides is related to kernicterus. In our case, silver sulfadiazine was applied after the fetus was delivered. Additionally, imipenem was given after cesarean delivery.

Pregnancy causes tremendous neurological and endocrine changes, including an activated renin-angiotensinaldosterone system [15] and an increased level of cortisol and the catecholamine adrenaline [16,17]. Heart disease and heart failure following pregnancy-induced hypertension $[18,19]$ and gestational diabetes [20] are not uncommon in pregnant women. It is reasonable to presume that severe burns might aggravate the pathological changes of gravida and result in a deteriorative outcome based on the current knowledge on pathological changes for pregnancy and severe burns. Because related reports and research are scarce, the collection and summarization of more clinical data are needed.

\section{Conclusions}

In summary, the timely termination of pregnancy at the early stage after injury and appropriate modification of the volume of solution for fluid resuscitation based on vital signs and urine output of the patient are two pivotal elements for the success of this case. However, the exact status of hemodynamics, including the heart function and circulation volume, remained uncertain due to the deficiency in invasive monitoring. The collection of more precise data will be very helpful for the decisionmaking concerning pregnant women with a severe burn injury in the future.

\section{Consent}

Written informed consent was obtained from the patient for publication of this case report and any accompanying images. A copy of the written consent is available for review by the Editor of this journal.

Competing interests

The authors declare that they have no competing interests.

\section{Authors' contributions}

YS collected the clinical data, performed the statistical analysis, and drafted the manuscript. XZ formulated the clinical treatment programs and helped to draft the manuscript. B-GH and W-KW participated in the clinical treatment. YL 
revised the manuscript for important intellectual content and the translation. All authors read and approved the final manuscript.

Received: 22 March 2014 Accepted: 10 December 2014

Published online: 28 May 2015

\section{References}

1. Mabogunje OA. Burns injuries during pregnancy: an African series. J Natl Med Assoc. 1990;82:641-4.

2. Rezavand N, Seyedzadeh A. Maternal and Foetal Outcome of Burns During Pregnancy in Kermanshah, Iran. Ann Burns Fire Disasters. 2006;19(4):174-176.

3. Karimi H, Momeni M, Momeni M, Rahbar H. Burn injuries during pregnancy in Iran. Int J Gynaecol Obstet. 2009;104:132-4.

4. Mokube JA, Verla VS, Mbome VN, Bitang AT. Burns in pregnancy: a case report from Buea Regional Hospital, Cameroon. Pan Afr Med J. 2009;3:21.

5. Mabrouk AR, El-Feky AE. Burns during pregnancy: a gloomy outcome. Burns. 1997;23:596-600

6. Rode H, Millar AJ, Cywes S, Bloch CE, Boes EG, Theron EJ, et al. Thermal injury in pregnancy - the neglected tragedy. S Afr Med J. 1990;77:346-8.

7. Maghsoudi H, Samnia R, Garadaghi A, Kianvar H. Burns in pregnancy. Burns. 2006;32:246-50

8. Rezavand N, Seyedzadeh A, Soleymani A. Evaluation of maternal and foetal outcomes in pregnant women hospitalized in Kermanshah Hospitals, Iran, owing to burn injury, 2003-2008. Ann Burns Fire Disasters. 2012;25:196-9.

9. Polko LE, McMahon MJ. Burns in pregnancy. Obstet Gynecol Surv. 1998:53:50-6.

10. Amy BW, McManus WF, Goodwin CW, Mason Jr A, Pruitt Jr BA. Thermal injury in the pregnant patient. Surg Gynecol Obstet. 1985;161:209-12.

11. Chen H. Normal puerperium and lactation. In: Zhuang Y, editor. Modern obstetrics. 2nd ed. Beijing: Science Press; 2009. p. 173. In Chinese.

12. Hayek S, Ibrahim A, Abu Sittah G, Atiyeh B. Burn resuscitation: is it straightforward or a challenge? Ann Burns Fire Disasters. 2011;24:17-21.

13. Rayburn W, Smith B, Feller I, Varner M, Cruikshank D. Major burns during pregnancy: effects on fetal well-being. Obstet Gynecol. 1984;63:392-5.

14. Fox Jr CL. Silver sulfadiazine-a new topical therapy for Pseudomonas in burns. Therapy of Pseudomonas infection in burns. Arch Surg. 1968:96:184-8.

15. Smith A, Barclay C, Quaba A, Sedowofia K, Stephen R, Thompson M, et al. The bigger the burn, the greater the stress. Burns. 1997;23:291-4.

16. Rainey WE, Rehman KS, Carr BR. Fetal and maternal adrenals in human pregnancy. Obstet Gynecol Clin North Am. 2004;31:817-35.

17. Hussein W, Lafayette RA. Renal function in normal and disordered pregnancy. Curr Opin Nephrol Hypertens. 2014;23:46-53.

18. Wanderer JP, Leffert LR, Mhyre JM, Kuklina EV, Callaghan WM, Bateman BT. Epidemiology of obstetric-related ICU admissions in Maryland: 1999-2008* Crit Care Med. 2013:41:1844-52.

19. Burlingame J, Horiuchi B, Ohana P, Onaka A, Sauvage LM. The contribution of heart disease to pregnancy-related mortality according to the pregnancy mortality surveillance system. J Perinatol. 2012;32:163-9.

20. Berger H, Crane J, Farine D, Armson A, De La Ronde S, Keenan-Lindsay L, et al. Maternal-Fetal Medicine Committee, Executive and Council for the Society of Obstetricians and Gynaecologists of Canada. Screening for gestational diabetes mellitus. J Obstet Gynaecol Can. 2002;24:894-912.

\section{Submit your next manuscript to BioMed Central and take full advantage of:}

- Convenient online submission

- Thorough peer review

- No space constraints or color figure charges

- Immediate publication on acceptance

- Inclusion in PubMed, CAS, Scopus and Google Scholar

- Research which is freely available for redistribution 